\title{
SIMULATION AND ANALYSIS OF LOW COST WEEDER
}

\author{
Rajashekar M ${ }^{1}$, V K Heblikar ${ }^{2}$, S.Mohan Kumar ${ }^{3}$ \\ ${ }^{I}$ Research Scholar, Mech. Engg. Department, SDMCET, Dharwad, Karnataka, INDIA \\ ${ }^{2}$ Research Scholar \& Head, Mech. Engg, Department, SDMCET, Dharwad, Karnataka, INDIA \\ ${ }^{3}$ Principal, SDMCET, Dharwad, VTU, Belgaum, INDIA
}

\begin{abstract}
Weed management is one of the tedious operations in crop production. Because of labor costs, time and fully manual weeding is unfavorable. Hence effort is made to design and develop efficient Farm equipment to perform weeding without using electric power. This paper presents modeling, simulation, analysis, fabrication and testing of low cost three row weeder. The conception and key characteristics of simulation based design and the advantage of using it to design the driving mechanism of three row weeding equipment were discussed. The structure and mechanical parts of weeder were designed using CATIA with detail, including its threedimensional modeling, assembly, interference checking, kinematics simulation, and two-dimensional engineering-drawing conversion etc. Later 3-D cad model is saved as (.stp) format and imported in ANSYS work bench environment and checked for Multibody dynamics simulation and Finite element analysis is done for safe design. The result shows that simulation based design technology can shorten the design \& development period and reduce design cost.. The machine would be very useful for poor farmers. The cost of the commercial model of the equipment was estimated at Rs6500/-. The functional efficiency result of the manually operated weeder cum feeder on loamy soil was $81.4 \%$, clay soil was $86.5 \%$ and sandy soil was $89.4 \%$ on of these soils. The overall machine field efficiency was $88.82 \%$.
\end{abstract}

Keywords: Simulation, CATIA design, MBD, FEA, ANSYS workbench, Farm equipment, Weeder.

\section{INTRODUCTION}

Traditional farming practices have evolved over the years for various processes [6].Historically; agricultural development played a central role as a driver of rural poverty reduction. However, recent trends show in slowing down of agricultural productivity growth and the marginalization of poor farmers [9]. In India Rs. 4,800 million worth of crop is being lost every year due to weeds [5]. On average, the cost of weeding comes to Rs. 945 per ha, out of the total cost of cultivation of Rs. 3000 per ha for agricultural crops [4].

Weed control is becoming an expensive operation in crop production. Majority of Indian farmers use hand-hoe for weeding which requires 40-60 labourers for weeding one hectare of land [3]. The effects of various shapes of blades of bullock-drawn blade harrow on depth of operation, weeding efficiency and crop yield was studied [2] . Six different blade shapes viz., convex, concave, $1200 \mathrm{~V}$ shape, $1600 \mathrm{~V}$ shape, serrated edge and tyne cum blade were compared with straight blade. Maximum draft of $450 \mathrm{~mm}$ wide blade harrow was 286 $\mathrm{N}$. Power requirement of the blade harrows was $0.20-0.27 \mathrm{~kW}$. Human energy predominantly used one other for almost all operation in Indian agriculture. Even in specialized operation as rice transplanting, horticultural plantation of crops, hoeing and weeding, picking of cotton, human power is still only source of energy.
Mechanical weeding is preferred to chemical weeding because weedicide application is generally expensive, hazardous and selective. Besides, mechanical weeding keeps the soil surface loose by producing soil mulch which results in better aeration and moisture conservation. Keeping in view of the above facts, an engine operated weeder was designed, developed and tested in field [8].

In general equipment/machinery fabrication industries, CAD technology has been very widely applied to various fields. But Farm machinery still remains an the primary stage, which based on hand work such as objects, models and drawings and samples to complete the whole process of Farm machinery body design method without using the modern CAD design software tools. At present, foreign farm machinery companies have started to use CAD modern technology, while problems such as not precise enough, long design cycle still exist in domestic agricultural machinery companies.

\subsection{Simulation}

Simulation is a new methodology of virtually testing a product design. Various approaches can be used, including Multibody Dynamics Simulation (MBD), Finite Element Analysis (FEA), or a combination of both. The design is modeled, often starting with Computer Aided Design (CAD) data, and then virtually tested to verify that the design will function as expected under defined operating conditions. The results from the simulation provide insight into the behavior of the design 
and help engineers make design changes and improvements. The use of simulation in the design process can bring many benefits that will save both time, money, innovate faster and get your products to market sooner.

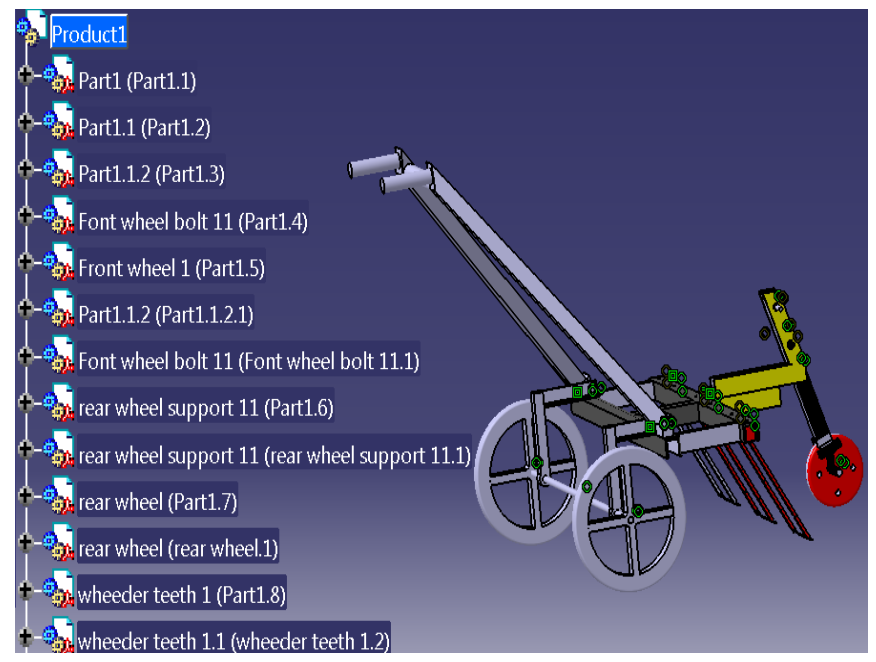

Fig-1: CATIA Design Assembly

\subsection{Finite Element Analysis}

The three important steps in ANSYS programming used for Finite Element Analysis are:

i) Preprocessing ii) Solution iii) Post processing

After preparing a solid geometry of weeder the important steps are meshing and applying loading and boundary conditions in the preprocessor so that simulation can be run to get a solution and generate results in the post-processor. A very fine mesh of the model gives good result. Hence a designer has to model it optimally i.e. placing fine mesh only at critical area; and coarse mesh at other. So that the run time is less and also the accuracy is not much affected.

\section{MATERIALS AND METHODS}

\subsection{Base Frame}

A base frame was made by welding two $40 \times 6 \mathrm{~mm}$ size MS $\mathrm{C}$ - iron sections $825 \mathrm{~mm}$ long so as to have $\mathrm{H}$ section. The tool bar was connected to a frame made of two $25 \times 6$ mrn size MS angles. The frame was fitted to the weeding attachment at the rear. In front of the base plate for mounting the front wheel frame was made on $6 \mathrm{~mm}$ mrn thick MS plate of $825 \times 170$ mrn dimensions.

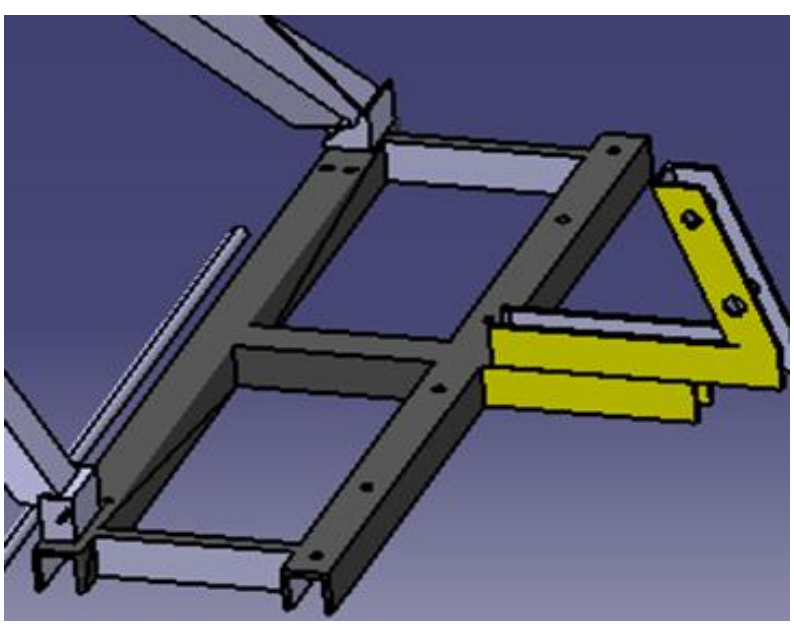

Fig -2: CATIA 3-D model of Base Frame

\subsection{Driving Wheels}

Two $300 \mathrm{~mm}$ diameter driving wheels were made using fibre molded rim. Stiffening rods of $15 \mathrm{mrn}$ diameter and $99.48 \mathrm{~mm}$ long 4 in numbers were used as spokes on the central hub. The $50 \mathrm{~mm}$ long hub was made to suit the $15 \mathrm{mrn}$ size round MS rod which is the central axle of the ground wheels.

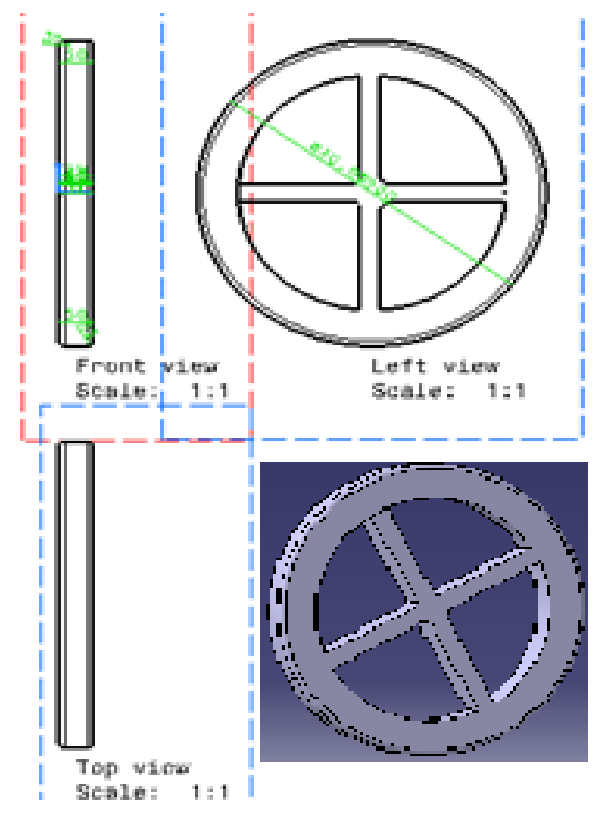

Fig -3: CATIA Drafting of Wheel

\subsection{Front Wheel}

A $150 \mathrm{~mm}$ diameter castor wheel was fitted at the front frame bracket of the machine to achieve economic weeding operation with reduced effort. . 


\subsection{Weeder Blade}

The weeder blade was assumed to be a simply supported beam subjected to a uniformly distributed load of $150 \mathrm{~N} / \mathrm{m}$. Based on it the thickness sweep of blade, was calculated to be $3 \mathrm{~mm}$ The two different shapes weeder blades are designed according to need of different soil properties .

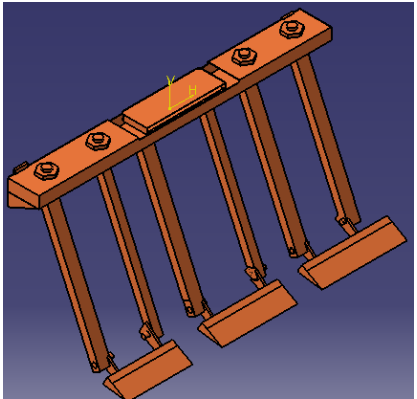

a) Trapezoidal shape Blade

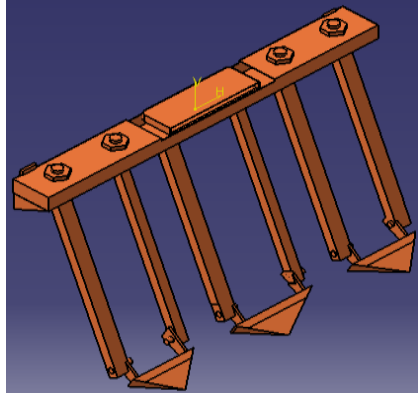

b) V-shape Blade
Fig -4: CATIA 3-D Drafting of Frame Weeder Blade

\section{DESIGN METHODOLOGY}

The force required to uproot some weeds determined by using rope was by pulling through a spring balance and the force at the point of weed removal will be recorded. The machine was designed based on the principle of weed stem failure due to shear, and soil or root failure due to impact and abrasion.

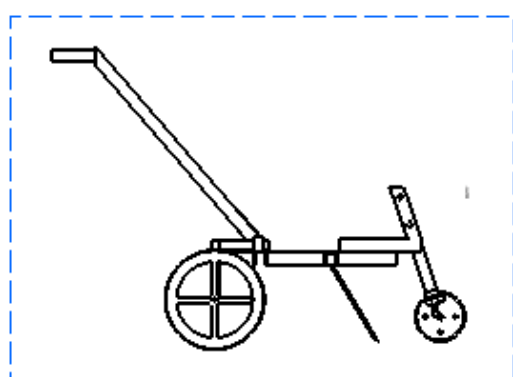

Side View
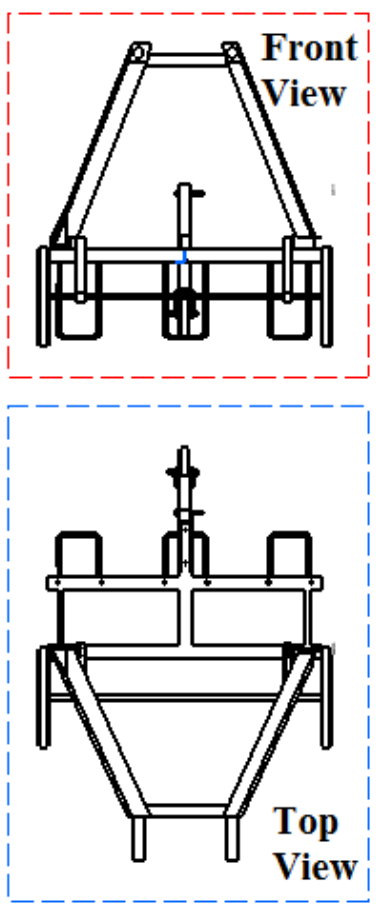

The design process can be viewed as an optimization process to find structures, mechanical systems, and structural parts that fulfill certain expectations towards their economy, functionality, and appearance using simulation based design process as shown in block diagram.

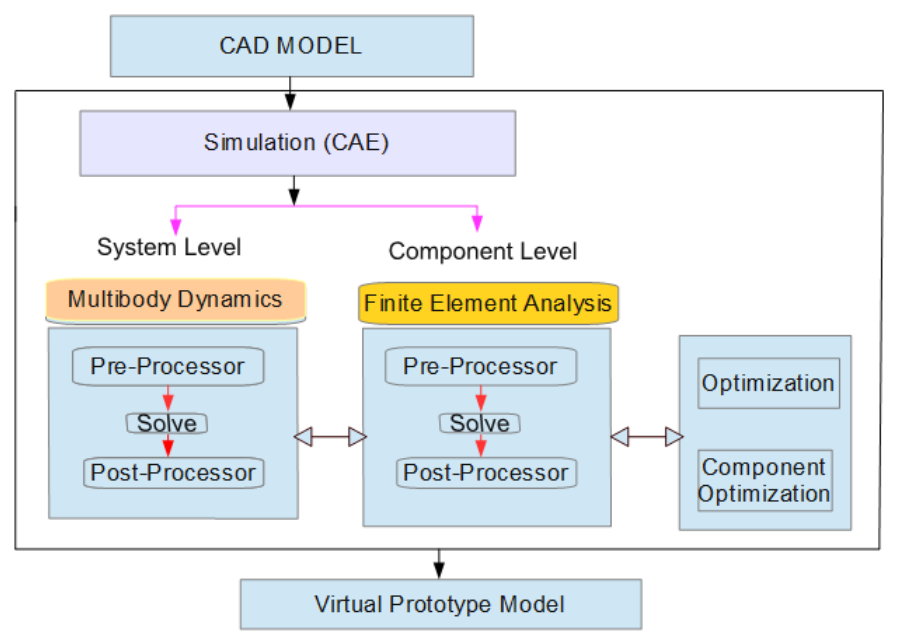

Fig- 6 Simulations Based Design Approach

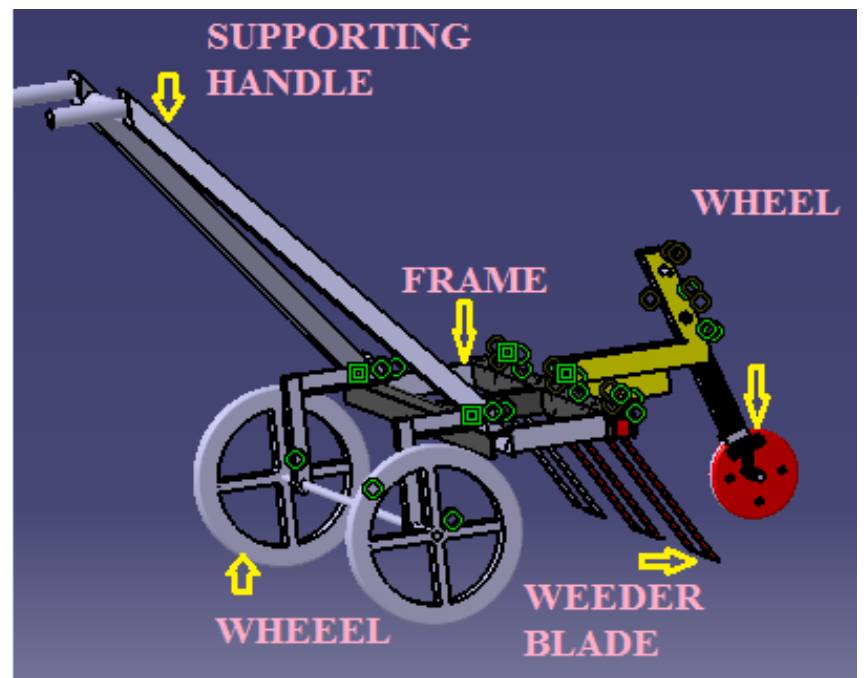

Fig 7 Simulation of the components in CATIA

Fig- 5: CATIA 2-D Drafting 


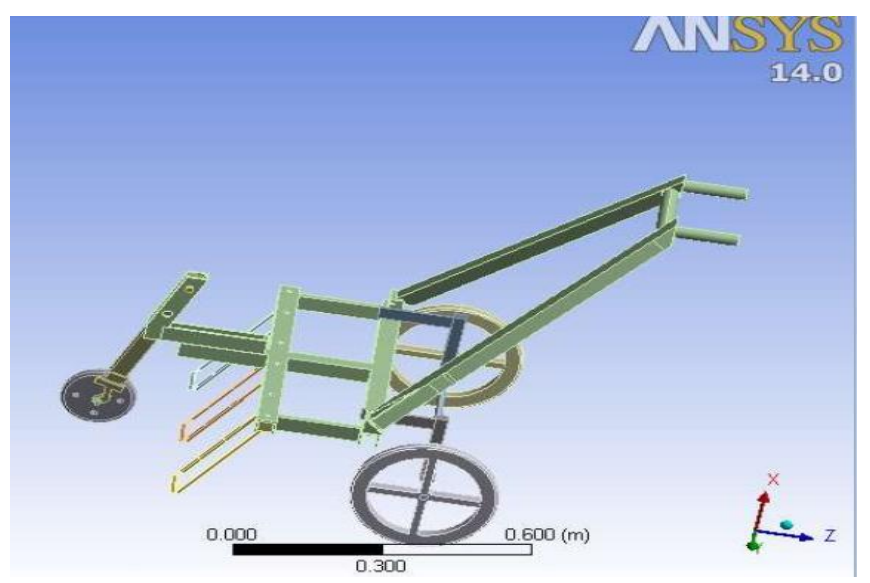

Fig -8 MBD analysis Using ANSYS

The machine design calculations was by the use of first principle of mechanics to determine the force requirement by the frame and the blade, bending moment, tensional requirement to determine the machine shaft size and other component parts. The component parts and assembly drawing of the machine was carried out.

\subsection{Soil Parameters:}

The soil properties relevant to the design of weeder were identified as soil type, moisture, bulk density and cone index.The type of soil was sandy black soil were experiment was conducted. Moisture content of soil plays an important role for the growth of the crop hence following Soil resistance and Moisture content of soil are considered as given in table 2 .

Table -1 Soil Properties:

\begin{tabular}{|l|l|l|l|}
\hline Sl.No. & Type of Soil & $\begin{array}{l}\text { Soil } \\
\text { Resistance } \\
\text { Mpa }\end{array}$ & $\begin{array}{l}\text { Optimum } \\
\text { moisture } \\
\text { content }\end{array}$ \\
\hline 1 & Sandy Soil & 0.21 & $3.5 \%$ \\
\hline 2 & Loamy Soil & 0.34 & $5.8 \%$ \\
\hline
\end{tabular}

\subsection{Power Development by the Human Worker}

The average power availability in sustained working from a male agricultural worker is consider as 60WATTS $(0.06)$ while for a female worker it is consider as 48 Watts $(0.048 \mathrm{kw})$ and for child worker as 30 watts $(0.030 \mathrm{~kW})$.

According to Campbell (1990) the power of useful work done by human being is given by

$$
\mathrm{HP}=0.35-0.092 \log \mathrm{t}
$$

Now, for 3-4 hours continuous work the power development by the operator would be $0.10-0.13 \mathrm{HP}$ say $0.11 \mathrm{hp}$ or $0.08 \mathrm{KW}$ We know that

Power, W=push (N) X speed (m/s)/1000, KW

Push $=\mathrm{W} X 1000 /$ speed $(\mathrm{m} / \mathrm{s}), \mathrm{N}$

\subsection{Analysis Results}

A three dimensional model of the new designed weeder structure was designed using CATIA V5.

Table 2: Material Properties

\begin{tabular}{|l|l|}
\hline Young's Modulus & $210 \mathrm{GPa}$ \\
\hline Compressive Strength & $2.5 \mathrm{e}+008 \mathrm{~Pa}$ \\
\hline Density & $7850 \mathrm{~kg} \mathrm{~m}^{\wedge}-3$ \\
\hline Coefficient of Thermal Expansion & $1.2 \mathrm{e}-005 \mathrm{C}^{\wedge}-1$ \\
\hline Specific Heat & $434 \mathrm{~J} \mathrm{~kg}^{\wedge}-1 \mathrm{C}^{\wedge}-1$ \\
\hline
\end{tabular}

Then checked computational simulation of the bottom was carried out by ANSYS workbench software utilizing the finite element method.

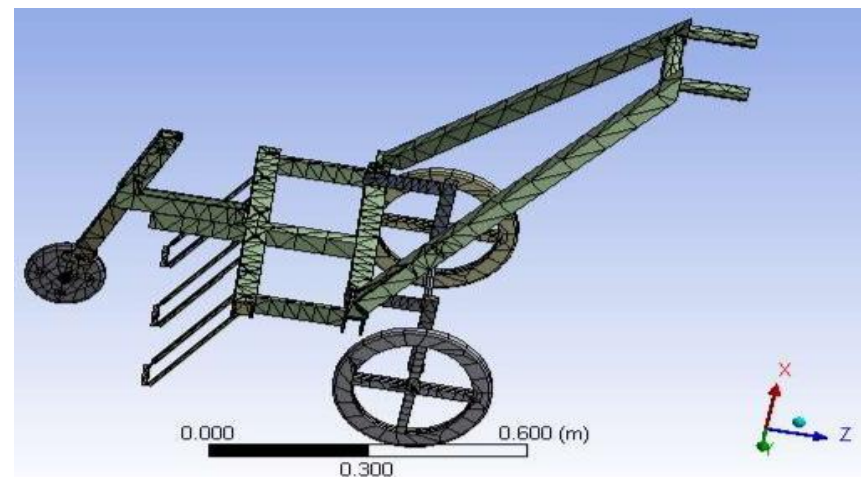

Fig -9 FEA Meshed Model

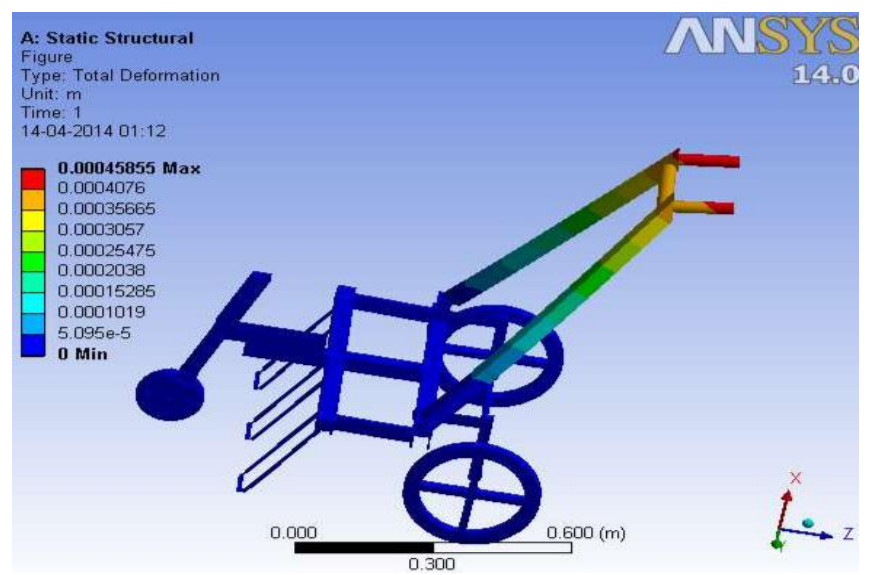

Fig -10 Total Deformation 


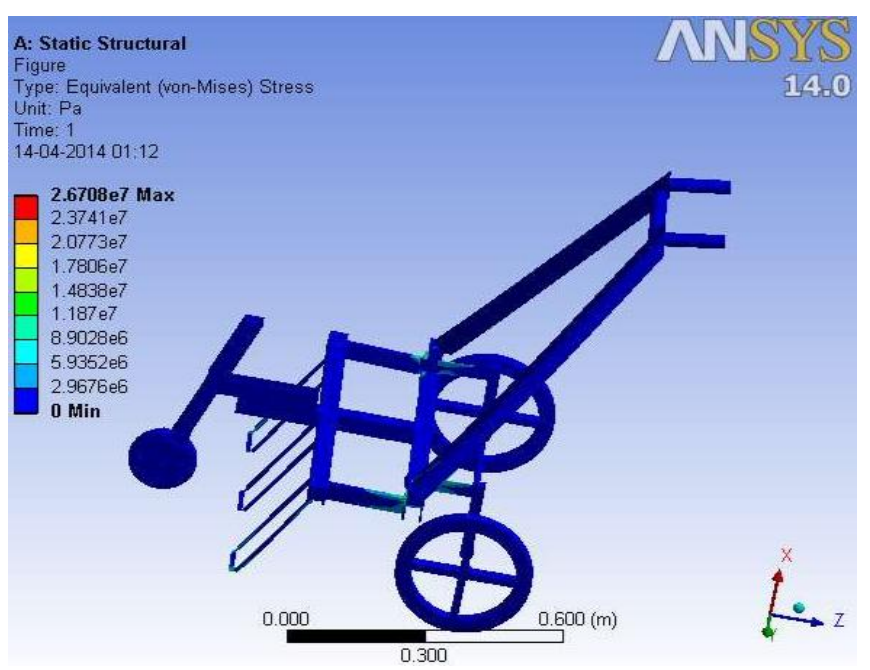

Fig -11 Equivalent (Von-misses) Stress

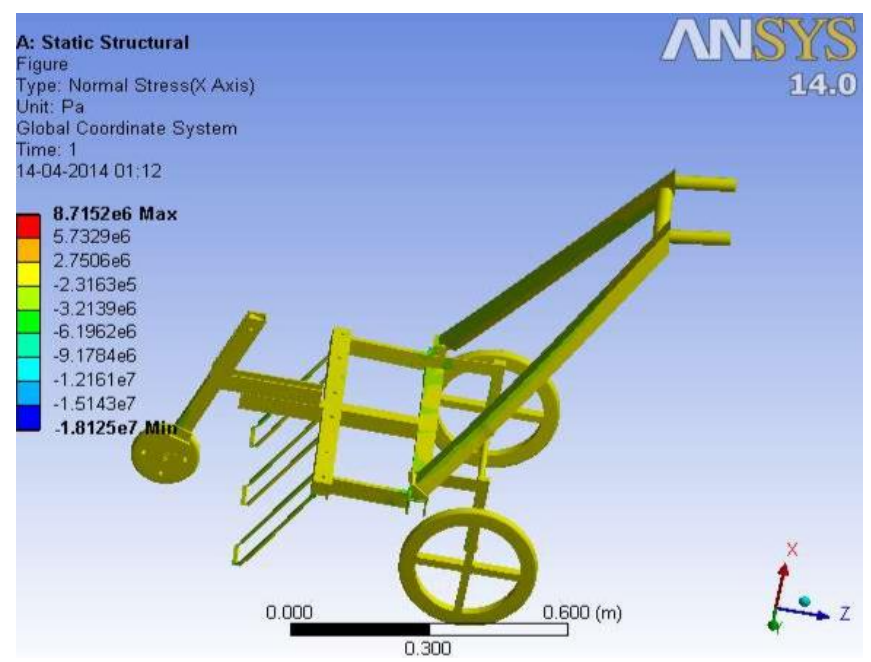

Fig -12 Normal Stress

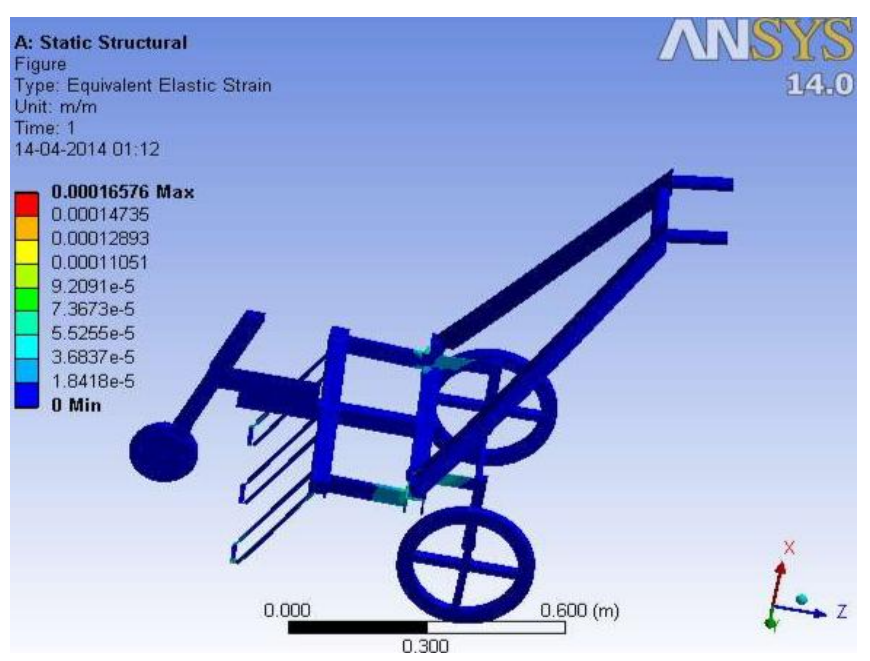

Fig -13 Equivalent Strain

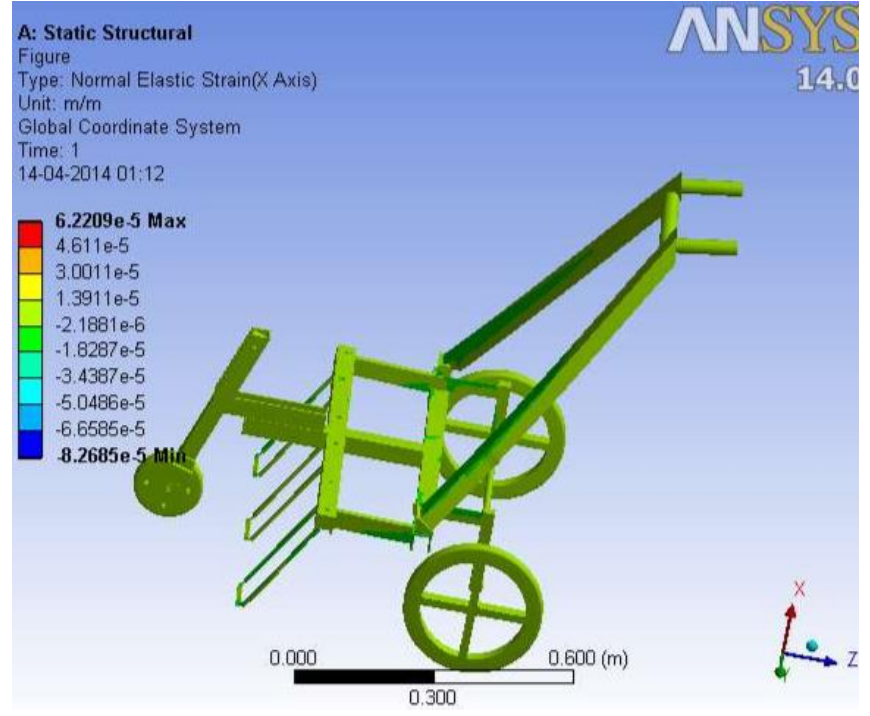

Fig -14 Normal Elastic Strain

\section{PERFORMANCE EVALUATION}

The equipment was evaluated in the field to determine; theoretical field capacity, effective field capacity, field efficiency, weeding efficiency and fuel consumption rate.

Weeding efficiency was determined by removing manually the weeds in $1 \mathrm{~m} \times 1 \mathrm{~m}$ area of the farm, the weeds was weighed and recorded. The process was repeated in five randomly selected locations on the farm. The average weight of the weeds in $1 \mathrm{~m} \times 1 \mathrm{~m}$ area was calculated for the types of soil. The average weight of the weeds in $1 \mathrm{~m} \times 1 \mathrm{~m}$ area after pass of the weeder through the farm was deducted from the actual weight of the weeds in $1 \mathrm{~m} \times 1 \mathrm{~m}$ area. Thus, functional efficiency was determined from the relation:

\section{(weights of weed removed-100) \\ Functional efficiency $=$ Actual weight of weed}

Numbers of weed plants were counted at random in a square meter area at 3 different places before and after operating the machine. From the mean values, weeding efficiency of the machine was determined.

\section{RESULTS AND DISCUSSIONS}

The displacement Vector Sum and Von Misses Stress is variation maximum at weeder blade, frame and handle section such as $0.402 \mathrm{~mm}$ and $2.6704 \mathrm{e} 7 \mathrm{~Pa}$ respectively which are in with in safe limit.

Weeding can be done in between standing rows of crops like cotton, tapioca and grape whose row to row spacing is more than $450 \mathrm{~mm}$. More area (around $1 \mathrm{ha}$ ) can be covered in a day using only one or two operators. Cost of weeding by this 
machine comes to only one third of the corresponding cost by manual labourers.

Table -3: Weeding test result on loamy soil

\begin{tabular}{|l|l|l|}
\hline Ares & Weed removed in $\mathrm{Kg}$ & Total weed in $\mathrm{Kg}$ \\
\hline A & 0.30 & 0.31 \\
\hline B & 0.32 & 0.42 \\
\hline B & 0.20 & 0.28 \\
\hline MEAN & 0.27 & 0.33 \\
\hline
\end{tabular}

Functional efficiency $=(0.27 / 0.33) \times 100=81.81 \%$

Table-4: Weeding test result on sandy soil

\begin{tabular}{|l|l|l|}
\hline Ares & Weed removed in $\mathrm{Kg}$ & Total weed in $\mathrm{Kg}$ \\
\hline $\mathrm{A}$ & 0.05 & 0.06 \\
\hline $\mathrm{B}$ & 0.03 & 0.04 \\
\hline B & 0.07 & 0.07 \\
\hline MEAN & 0.05 & 0.056 \\
\hline
\end{tabular}

Functional efficiency $=(0.05 / 0.56) \times 100=89.28 \%$

The summarized performance data on the weeder was as follows: Adjustable Row width and height

Age of the crop: Two-Three weeks

Effective field capacity $=0.10$ halh

Depth of operation $=25 \mathrm{~mm}, 30 \mathrm{~mm}, 35 \mathrm{~mm}$

Overall Weeding efficiency $=88.82$ per cent

Initial cost of weeder $=$ Rs. 6500

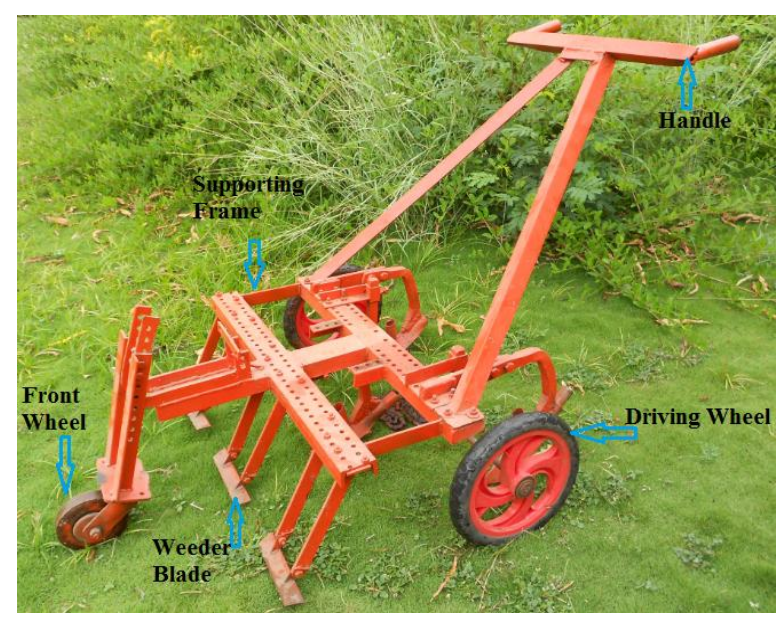

Fig -15: Fabricated Low Cost Weeder

\section{CONCLUSIONS}

A three row weeder was efficiently designed first using CATIA and analyzed using ANSYS WORKBENCH. The fabrication of Low cost Weeder is done with locally available material and tested at the department of mechanical Engineering test field. The machine performed excellently as a weeder and as well as intercultivator. It works as a mower when cutting height is between $20 \mathrm{~mm}$ and $40 \mathrm{~mm}$, however it works well as a weeder between cutting height of $25 \mathrm{~mm}$ below the ground and $10 \mathrm{~mm}$ above the ground level. The machine would be very useful for poor farmers. The functional efficiency result of the manually operated weeder cum feeder on loamy soil was $81.4 \%$, clay soil was $86.5 \%$ and sandy soil was $89.4 \%$ on of these soils. The overall machine field efficiency was $88.82 \%$ The weeder has a field capacity of $0.1 \mathrm{ha} / \mathrm{h} .2$. Cost of weeding by this machine comes to only one-third of the corresponding cost by manual laborers. For achieving ease of operation and increase in weeding capacity/ha Petrol start Kerosene engine is mounted an the base frame and other farm operations can also automated.

\section{ACKNOWLEDGEMENTS}

We express our first and fore most panamas to his Holiness Dr.Ma.Gha.Cha.Channabasava Pattadevaru, Dr.Bheemanna Khandre Founder President, Er.Eshwar Khandre president SVE Society.The authors acknowledge with thanks to Principal Dr.Bipin Bihari Lal BKIT,Bhalki who made this Endeavour possible and also express our gratitude and indebtedness to SDMCET Dharwad Research centre and his holiness of Poojya Dr. D. Veerendra Heggade, president SDME Society for providing us an opportunity to undergo research work successfully.

\section{REFERENCES}

[1]. Weide, R. Y. V. D., P. O. Bleeker, V. T. J. M. Achten, L. A. P. Lotz, F. Fogelberg, and B.Melander. 2008. Innovation in mechanical weed control in crop rows. Weed Research 48 (3): 215-224.

[2]. Tillett, N.D., Hague, T., Grundy, A.C. and Dedousis, A.P. 2008. Mechanical within-row weed control for transplanted crops using computer vision. Biosystems Engineering 99(2): 171-178.

[3]. Cloutier, D. C., R. Y. V. D. Weide, A. Peruzzi, and M. L. Leblanc. 2007. Mechanical weed management. In NonChemical Weed Management. Upadhyaya, M. K. and R. E. Blackshaw, ed. 111-134. CAB International.

[4]. Gopal U.Shinde, J.M.Potekar, R.V.Shinde,Dr.S.R.Kajale " Design Analysis of Rotary Tillage Tool Components by CADtool:Rotavator" International Conference on Environmental and Agriculture Engineering IPCBEE vol.15(2011), Singapore [5]. Griepentrog, H.W., Norremark, M and Nielsen, J. 2006. Autonomous intra-row rotor weeding based on GPS. Proceedings: CIGR World Congress Agricultural Engineering for a Better World, Bonn, Germany, 3-4 September.

[6]. Gurusamy, T. 1988. Effect of blade shapes on the performance of blade hoe.Agricultural Engineering Today, 12(2):25-27.

[7]. Natarajan, P. 1987. Introduction to pesticides. Pesticide Information, 8 (2) : 2223.

[8]. TajuddinA; Job TV. 1997. Min tiller for weeding and interculture. The Hindu dated October $2: 28$. 
[9]. Tajuddin A; Karunanithi R; Swaminathan K R. 1991. Design development and testing of an engine operated blade harrow for weeding. Indian Journal of Agricultural Engineering, 1(2): $137-140$

[10]. Duraisamy V M; Tajuddin A.1999. Rotary weeder for mechanical interculturing in sugarcane. Agro India, 3 (1-2) : 48. 